\title{
An operational ocean forecast system incorporating NEMO and SST data assimilation for the tidally driven European North-West shelf
}

\author{
Author List \\ O'Dea $\mathrm{EJ}^{1}$, Arnold $\mathrm{AK}^{1}$, Edwards $\mathrm{KP}^{1}$,Furner $\mathrm{R}^{1}$, Holt $\mathrm{JT}^{2}$, Hyder $\mathrm{P}^{1}$, Liu $\mathrm{H}^{2}$ Martin $\mathrm{MJ}^{1}$, \\ Siddorn $\mathrm{JR}^{1}$, Storkey $\mathrm{D}^{1}$, While $\mathrm{J}^{1}$ \\ Affiliation \\ ${ }^{1}$ Met Office, Exeter, UK \\ ${ }^{2}$ National Oceanography Centre, Liverpool, UK
}

\begin{abstract}
A new operational ocean forecast system, the Atlantic Margin Model implementation of the Forecast Ocean Assimilation Model (FOAM-AMM), has been developed for the European North West Shelf (NWS). An overview of the system is presented including shelf specific developments of the physical model, the Nucleus for European Modeling of the Ocean (NEMO), and the Sea Surface Temperature (SST) data assimilation scheme. Initial validation is presented of the tides and model SST. The SST skill of the system is significantly improved by the data assimilation scheme. Finally, an analysis of the seasonal tidal mixing fronts shows that these in general agree well with observation, but data assimilation does not significantly alter their positions.
\end{abstract}

\section{Lead Author's Biography}

In 2004, after completing a PhD. in computational fluid dynamics, Enda O'Dea joined the Met Office to work in ocean modelling. He now develops ocean forecast models in the Ocean Forecasting Research and Development (OFRD) group. Recently, the group has overseen the transition from a POLCOMS based forecast system to a NEMO based forecast system for the shelf seas around the U.K. Enda's principal research area is in shelf seas forecasting and interests include the dynamics of tides, seasonal stratification, shelf slope currents and regions of fresh water influence.

\section{Introduction}

The North-West European shelf seas have been the subject of numerous hydrodynamic models of increasing complexity and sophistication. ${ }^{1,2}$ 3D baroclinic hydrodynamic models have evolved from research tools into operational forecast systems at operational centres. ${ }^{3,4}$ Recently, in addition to operational forecasts for hydrodynamic variables, ecosystem models have been implemented operationally. ${ }^{5}$ Such ecosystem models provide model estimates of biogeochemical variables such as chlorophyll in complement to remote Earth observations. ${ }^{6}$

In global ocean and basin scale modeling, data assimilation has proved an invaluable component for operational forecasting. ${ }^{7}$ For the shelf seas however ${ }^{8}$, the necessary inclusion of shorter temporal and spatial scale processes, in particular in relation to the interaction of the tides and the shelf, has discouraged the widespread use of data assimilation in operational systems. In this paper we outline the development of an operational modeling system for both physical and biogeochemical parameters in the North-West European continental Shelf (NWS) that includes assimilation of Sea Surface Temperature (SST) data. 
In the Met Office's Forecasting Ocean Assimilation Model (FOAM) ${ }^{9}$ system, the core dynamical model has recently ${ }^{10}$ migrated to the Nucleus for European Modeling of the Ocean (NEMO). ${ }^{11}$ Using NEMO allows short-term operational ocean forecasting systems to employ the same fundamental ocean model code as in the global and basin scale seasonal and climate prediction systems at the Met Office. Adopting NEMO is also beneficial to the group by becoming part of a large and active cross-institutional developer base. Like the open ocean, the strategy for the assimilative shelf seas forecasting system described here is to apply NEMO as the physics engine. Assimilation of SST adapts the existing open ocean FOAM system in a manner suitable for application in the shelf seas. Whilst NEMO is also coupled with the European Regional Seas Ecosystem Model (ERSEM) ${ }^{12,13}$ for ecosystem modeling, this paper details only the physics and assimilation. The coupled physicsecosystem will be the subject of a following paper. ${ }^{13}$

Previously, operational modeling of the NWS at the Met Office utilised the Proudman Oceanographic Laboratory (now National Oceanography Centre) Coastal-Ocean Model System (POLCOMS) ${ }^{14,15}$. NEMO was developed as an open ocean model and therefore lacked many of the shelf-specific features found in models such as POLCOMS. It was therefore necessary to incorporate significant modifications to NEMO to make it suitable to replace POLCOMS as the operational model for shelf applications. It should be noted that the POLCOMS system is a well established and validated system ${ }^{16}$ and provides a reliable reference system from which to compare forecast skill in any new modelling system.

The operational shelf seas forecasting system is run in the Met Office operational suite on a daily cycle and forms part of the Europe-wide operational oceanography contribution to Global Monitoring for Environment and Security (GMES). The NEMO forecasting system documented in this work is now providing operational forecasts. Analyses and five day forecast products for the NWS are provided as part of the MyOcean project, the EC FP7 project that currently delivers the GMES Marine Core Service. ${ }^{17}$

The remainder of this paper is divided into the following sections. First the model domain and configuration are described. Second an overview of the model in general and specific enhancements that have been developed to tackle the shelf seas dynamics in particular are given. Third, the developments required for assimilation of SST on the shelf are described. Fourth, a preliminary validation of the system is detailed. Finally, conclusions and future developments are discussed.

\section{SYSTEM DESCRIPTION}

\section{Physical context: The North-West European shelf}

The Atlantic Margin Model (AMM) region shown, in Fig 1, covers the North-West European shelf and part of the North-East Atlantic ocean. A key feature dividing the shelf from the deep ocean is the shelf slope, running from Portugal to Norway. Associated with the shelf slope is the important Joint Effect of Baroclinity and Bottom Relief (JEBAR) ${ }^{18}$ process, which drives a poleward shelf slope current common to many eastern margins. Examples of other poleward eastern boundary currents in other regions include the coastal undercurrents of Chile and California, the Alaskan slope current and the bottom layer shelf break current of southwest Africa. ${ }^{19}$ The shelf slope itself varies in width and steepness. It is particularly steep along the Iberian slope to the west of Portugal and the Cantabrian slope to the north of Spain. The combination of step bathymetry and terrain following (sigma) coordinates requires special treatment for the modelling of Horizontal Pressure Gradients (HPG). The slope current is also variable and along the Iberian and Cantabrian slopes it is seasonal. It manifests itself as the Iberian Slope current during autumn and winter. ${ }^{20,21}$

Further north the shelf widens from the Aquitaine slope to the Armorican and Celtic shelf slopes with France to the east. The Celtic shelf slope is a major source of internal tides ${ }^{22}$ and enhanced mixing. ${ }^{23}$ Travelling northwards, the shelf slope encompasses the Celtic Seas ${ }^{24}$ of the English Channel, Irish Sea, and the Celtic, Irish, Malin and Hebrides shelves. Thereafter the shelf slope turns more eastward at the Faroes-Shetland ridge towards Norway with the North Sea to the south and the Faroese channels to the north. Finally, crossing the 
Norwegian trench to the south, the shelf slope travels parallel to the Norwegian coast towards the northern boundary of the domain.

The Faroese channels and the Wyville-Thomson Ridge are important areas for the return of the cold dense outflow from the Nordic seas. ${ }^{25,26}$ Accurate modelling of the overflow requires higher resolution models than is currently computationally possible for operational coupled physical-ecosystem models of the entire region. Careful attention is required at such overflows particularly in relation to the limitations of terrain following coordinates and steep bathymetry.

Although the main aim of the shelf model is in simulating the on-shelf properties, the off-shelf dynamics and the shelf slope current are also important as they impact cross-slope transport. Approximately $12.5 \%$ of the global tidal energy is transmitted into the Celtic Seas from the North Atlantic, with large tidal responses in the English Channel, Bristol channel and Irish Sea. ${ }^{24}$ The large tidal response results in large dissipation of tidal energy and an input of turbulent kinetic energy into the water column. The seasonal variation in both wind, which further adds to the production of turbulence, and heating, which adds buoyancy, leads to seasonally stratified and mixed regions. The balance between mixing created by wind and tide, and stratification by thermal heating, leads to tidal mixing fronts at the boundary between well mixed and stratified water columns. ${ }^{27}$ Thus accurate representation of tidal dynamics, turbulence production and dissipation, and the air-sea flux of momentum and heat are critical for modeling the regional dynamics. The effects of winds are not limited to turbulence production but also drive currents, which along with the buoyancy field provide the residual circulation. ${ }^{28}$ Furthermore, wind forcing in combination with atmospheric pressure can produce large and potentially dangerous storm surges in the North Sea. ${ }^{29}$ As such, a regional model must include the atmospheric pressure gradient forcing, and the interaction of tides and surges.

Sources of freshwater influence the baroclinic flow with inputs from rivers such as the Rhine leading to dynamically complex Regions Of Freshwater Influence (ROFI) ${ }^{30}$ and coastal currents. Sources of low saline water are not restricted to local riverine sources alone. Low saline water of Baltic origin, which may be considered as a large estuarine source, exchanges with relatively high saline North Sea water flowing into the Baltic in a dynamically complex transition area. The connection with the Baltic consists of the shallow sills and narrow straits of the Kattegat, the Sound, the Great Belt and the Little Belt. To resolve the flow through these channels requires relatively high resolution models ${ }^{31}$; where the resolution of the shelf model is not adequate to resolve them, fluxes between the Baltic and Kattegat must be specified as a special form of boundary condition. The dynamics are further complicated by the intrusion of the relatively deep Norwegian trench as far as the Skagerrak. This guides North Atlantic water along its slope into the Skagerrak, where it upwells and re-circulates. ${ }^{32}$ The outgoing current flowing along the Norwegian coast consists of both low saline Baltic and coastal water, and mixed North Sea and North Atlantic water. Thus any model of the region must be able to represent the complex combination of haline, bathymetric, heating, tidal and surge effects that all interplay in this region.

\section{Physical Model}

The model is designed to provide simulations of the on-shelf hydrodynamics, biogeochemistry and light environments of the NWS. The high socioeconomic interest in the area has led to an intensive modeling effort, with a variety of high-resolution models exploring specific dynamical regimes in detail. However, in the context of an operational forecast system that is coupled to sediment and ecosystem models, a regional approach that interconnects the variety of dynamical regimes is required. ${ }^{15}$ The existing coupled POLCOMS-ERSEM Medium Resolution Continental Shelf (MRCS) ${ }^{5}$ system is nested into the physics only $12 \mathrm{~km}$ POLCOMS-AMM model and has a resolution of approximately $7 \mathrm{~km}$. The new FOAM-AMM system extends the coupling of ERSEM outwards from the MRCS domain to cover the entire AMM region from $40^{\circ} \mathrm{S}, 20^{\circ} \mathrm{W}$ to $65^{\circ} \mathrm{N}, 13^{\circ} \mathrm{E}$. Thus FOAM-AMM replaces 
both the existing POLCOMS operational models, POLCOMS-AMM ${ }^{33}$ and MRCS with a single domain.

Fig 1 depicts the North-West Shelf Operational Oceanographic System (NOOS) bathymetry covering the AMM region, which is a combination of GEBCO 1' data and a variety of local data sources from the NOOS partners. The shelf break in Fig 1 has been highlighted by the $200 \mathrm{~m}$ isobath. Also depicted is the perimeter of the existing MRCS ${ }^{16}$ domain. In order to ensure that the cross-slope exchanges of momentum and tracers are well represented a hybrid s- $\sigma^{34}$ terrain following coordinate system is employed in those models in order to retain vertical resolution on the shelf, while allowing a reasonable representation of deep water processes.

The resolution of FOAM-AMM is $1 / 15^{\circ}$ latitude by $1 / 9^{\circ}$ longitude. The horizontal resolution of $\sim 7 \mathrm{~km}$ lies between typical shelf wide resolution $(\sim 12 \mathrm{~km})$ and high-resolution limited-area models $(1.8 \mathrm{~km})$ sufficient to resolve the dominant fine scale physics on the shelf. ${ }^{28}$ It is not sufficient to resolve the internal Rossby radius on the shelf, which is of the order $4 \mathrm{~km}$, but well resolves the external Radius $(\sim 200 \mathrm{~km})$. Ideally the model would be of sufficient resolution to resolve both the internal and external radii, i.e. a resolution of the order $<2 \mathrm{~km}$. At present the computational cost of such a system make this impractical for coupled hydrodynamic-ecosystem operational forecasts.

The model bathymetry of POLCOMS is derived from the NOOS bathymetry. Some smoothing was applied to steep bathymetry such as the shelf break in the derivation of the existing $12 \mathrm{~km}$ AMM domain. This was to reduce HPG errors and improve the shelf slope current. $^{33}$ The $12 \mathrm{~km}$ POLCOMS-AMM bathymetry has been interpolated onto the replacement $7 \mathrm{~km}$ FOAM-AMM grid for inter-comparisons of the two systems. This ensures that the new physics does not gain advantage simply by having more bathymetric information in initial hindcast comparisons. In the initial validation stages NEMO-AMM was also run on the $12 \mathrm{~km}$ AMM grid for complete like for like comparisons at equivalent grid resolution.

The version of NEMO used in FOAM-AMM is v3.2. As it is necessary to model tides and surges, a non-linear free surface is implemented using a variable volume ${ }^{35}$ and time splitting methodology, using 'leap-frog' time stepping. The corresponding baroclinic time step is 150 seconds and the barotropic sub-cycle time step is 5 seconds. The momentum advection is both energy and enstrophy conserving. ${ }^{36}$ The lateral boundary condition on the momentum is free-slip. Horizontal diffusion of momentum is specified using both Laplacian and bilaplacian operators. Because FOAM-AMM utilises terrain following coordinates, it is necessary for the specification of Laplacian diffusion to be applied on geopotential surfaces to prevent spurious mixing in the vertical, and bilaplacian diffusion to be done on model levels to retain stability. The coefficients of laplacian and bilaplacian diffusion are $30.0 \mathrm{~m}^{2} \mathrm{~s}^{-1}$ and $1.0 \times 10^{10} \mathrm{~m}^{4} \mathrm{~s}^{-1}$ respectively. The total variation diminishing (TVD) scheme is used for tracer advection ${ }^{37}$. The tracer diffusion operator is only Laplacian and operates along geopotential levels. The tracer diffusion coefficient is $50 \mathrm{~m}^{2} \mathrm{~s}^{-1}$.

There are 32 terrain following coordinates in the vertical. The terrain following coordinate system is modified in two important ways. Firstly, as in ${ }^{34}$ and ${ }^{3}$, coordinates transition from a stretched S-coordinate system in the deep to a uniform $\sigma$-coordinate system on the shelf. Following ${ }^{33}$ the critical depth $h_{c}$ is defined at $150 \mathrm{~m}$ and the stretching parameters are defined as $\theta=6$ and $B=0.8$. Focused resolution in deep water at the surface is important for air sea fluxes of heat, freshwater and momentum, and the bottom in relation to the bottom boundary layer and bed friction. On the shelf uniform coordinates are preferred, as in shallow regions very small vertical cells will tend to result in violations of the vertical Courant-Friedrichs-Lewy (CFL) ${ }^{38}$ condition.

An additional modification to the coordinate system is based upon a $z^{*}-\sigma$ approach. ${ }^{39} \mathrm{~A}$ major constraint on terrain following coordinates occurs when adjacent ocean depths differ significantly leading to errors in the calculation of the HPG term. ${ }^{40}$ To reduce the error the initial $S-\sigma$-system is created using a smoothed envelope bathymetry rather than the input bathymetry itself. The motivation of the smoothing is to limit the steepness of the model levels 
to a given threshold. The threshold in FOAM-NEMO is chosen as 0.3. Thus for any two adjacent depths, $h_{i, j}^{e n v}, h_{i, j+1}^{e n v}$ in the envelope bathymetry, the relative difference is:

$$
r n=\frac{h_{i, j}^{e n v}-h_{i+1, j}^{e n v}}{h_{i, j}^{e n v}+h_{i+1, j}^{e n v}}<0.3
$$

The smoother only deepens, it does not shallow, the envelope bathymetry relative to the source bathymetry. The S- $\sigma$-coordinate system is then created based on the envelope bathymetry. However, $h$ is then masked for any grid cell that is lower than the input bathymetry. Hence, the coordinate slopes are never more than a desired threshold, at the expense of some vertical levels near steep bathymetry. At such points the levels intersect the bed and levels are lost. Fig 2 depicts a $z^{*}-\sigma$-coordinate system with its underlying smoothed envelope bathymetry. A hybrid $z^{*}-S-\sigma$ system provides one way of reducing HPG errors, that has the distinct advantage that the shape of the topography is not overly distorted by bathymetric smoothing. However, the underlying HPG scheme must also be suitably posed to minimize spurious velocities and cross-pycnocline mixing. Such errors result from inclined model surfaces relative to both geopotential surfaces and isopycnal surfaces. Furthermore, the $z^{*}-S-\sigma$ system does not resolve the issue of having a non-uniform surface box, which has implications for surface fluxes.

The standard HPG schemes in NEMO were found to give unacceptably large errors with the non-linear free surface, generating large erroneous velocities over steep topography such as the shelf break. Furthermore, these schemes were not able to deal with the hybrid vertical coordinate. To address this, a new HPG scheme was developed employing a pressure Jacobian method rather than the widely used density Jacobian method. This can be illustrated with the following formula:

$$
\left.\frac{\partial P}{\partial x}\right|_{z}=\left.\frac{\partial P}{\partial x}\right|_{S}-\left.\frac{\partial P}{\partial z} \frac{\partial z}{\partial x}\right|_{S}
$$

Here, $P$ is the pressure, $z$ is the non-transformed physical vertical coordinate and $s$ is the transformed vertical coordinate used in the model. $\partial /\left.\partial x\right|_{z}$ refers to the partial derivative in the horizontal defined on geopotential surfaces and $\partial /\left.\partial x\right|_{S}$ is the horizontal partial derivative defined on coordinate surfaces of the model coordinate system. A constrained cubic spline (CCS) method has been employed here to reconstruct the vertical density profile. The CCS reconstruction has the property of monotonicity. The vertical pressure profile can be calculated analytically, so the density Jacobian method is not needed. By splitting the second term of the two-term pressure gradient formula into left and right hand side parts, the pressure gradient can be calculated on the velocity cells without any weight parameter. In this formula, there is no hydrostatic consistency constraint. This pressure Jacobian HPG method can be applied to any hybrid vertical coordinate. For details about this HPG method, please refer to ${ }_{41}$. The combination of the new HPG scheme and the vertical coordinate scheme give good results in proximity to steep topography.

The non-linear free surface allows for the accurate representation of tides and surges. At the open boundaries tidal energy enters the domain via a Flather ${ }^{42}$ radiation boundary condition. Fifteen tidal constituents, calculated from a tidal model of the North-East Atlantic ${ }^{43}$, are specified for the depth mean velocities and sea surface elevation. As the AMM region covers a significant area, the equilibrium tide is also specified. In addition to the tidal boundaries, FOAM-AMM is one-way nested within the Met Office operational FOAM $1 / 12^{\circ}$ deep ocean model for the North Atlantic. ${ }^{10}$ Temperature and salinity are relaxed to the values specified by FOAM $1 / 12^{\circ}$ model over a ten point relaxation zone on the open boundaries using the flow relaxation scheme. ${ }^{44}$ Sea surface elevation and barotropic currents from the FOAM $1 / 12^{\circ}$ North Atlantic model are added to the tidal constituents via the Flather boundary condition.

Vertical turbulent viscosities/diffusivities are calculated using the Generic Length Scale (GLS) turbulence model. ${ }^{45}$ This allows for a choice from a range of closure schemes. In FOAM-AMM, the second-moment algebraic closure model of Canuto ${ }^{46}$ is solved with the two dynamical equations ${ }^{47}$ for the turbulence kinetic energy (TKE), $k$, and TKE dissipation, $\varepsilon^{48}$ 
The choice of this scheme is based upon results in the North-West European shelf with POLCOMS. ${ }^{49}$ Neumann boundary conditions on $k$ and $\varepsilon$ are applied at the surface and sea bed. The Craig and Banner ${ }^{50}$ surface wave mixing parameterization is also applied. The dissipation is limited under stratification using a Galperin ${ }^{51}$ limit of 0.267 . The bottom friction uses a spatially varying log layer based drag coefficient with a minimum drag coefficient set at 0.0025 .

River flow is specified for 320 European rivers. ${ }^{52}$ The river scheme in NEMO has been updated so temperature and salinity boundary conditions at river inflow points can be specified flexibly to better represent the vertical structure of different river outflows. Although this could be used for all rivers in the domain if data were available, in this work it is used for the Baltic flows through the Belt region, which are treated as rivers with specified temperature, salinity, and volume fluxes. The data for the flux between the Kattegat and the Baltic is derived from the Danish Hydrographic Institutes' Dynamics of Connected Seas (DYNOCS) experiment. ${ }^{3}$ In this configuration for other 'rivers' the temperature of the river water is specified as the SST of the model box at the river point and the river flow is specified by the river flow climatology. However, the river input is assumed to be of zero salinity.

The model is forced at the surface by fluxes from the global Met Office Numerical Weather Prediction (NWP) model. The NWP model has a horizontal resolution of approximately $25 \mathrm{~km}$ and incorporates 4-Dimensional Variational Data Assimilation (4DVAR). Three hourly mean fluxes of penetrating and non-penetrating heat fluxes (corrected for intramodel SST differences by a Haney flux correction term ${ }^{53}$ ), moisture fluxes, and hourly instantaneous fields of windspeed and surface pressure are applied. An atmospheric pressure gradient force is applied at the surface, which is important for surge modelling. The light attenuation coefficient varies in the horizontal depending on the undisturbed water depth following POLCOMS. This is a simple way of partially accounting for more turbid and thus less clear waters in shallow coastal waters.

\section{Data Assimilation system}

Data assimilation within FOAM-AMM is carried out using a modified version of the Analysis Correction scheme used in global FOAM. This system is described in ${ }^{10}$ and ${ }^{54}$ and consists of 3 stages. In the first stage a one-day model run is compared to observations using a First Guess at Appropriate Time (FGAT) scheme. In the second stage, observationminus-model differences (the innovations) are converted to model increments using an iterative $^{55}$ method to solve the Best Linear Unbiased Estimator (BLUE) equations. Finally, the model is rerun for the same day with an Incremental Analysis Update (IAU) scheme ${ }^{56}$ to update the model state using the pre-calculated increments. This three stage process is repeated for subsequent model analysis days.

Considerable modifications have been made to the global FOAM data assimilation methodology ${ }^{10}$ to enable it to be applied to shelf seas. The resulting algorithm is similar to the scheme described in ${ }^{57}$ and also the optimal interpolation part of the method of ${ }^{58}$. However, unlike these two methods our scheme does not assume a zero correlation length for forecast error. The most significant difference between data assimilation in the FOAM-AMM and global FOAM systems is that only SST data are assimilated. Temperature and salinity profile assimilation along with sea surface height assimilation are technically more challenging in the shelf environment and will be implemented as future developments to the system. As in ${ }^{10}$, data assimilated into FOAM-AMM are comprised of in-situ data and level 2 satellite SST data provided by the Global High-Resolution Sea Surface Temperature project (GHRSST, ${ }^{59}$ ). Insitu data are obtained from a variety of sources and include measurements taken by ships, moored buoys, and drifters. Satellite observations are obtained from the Advanced Microwave Scanning Radiometer-Earth observing system (AMSRE), the Advanced AlongTrack Scanning Radiometer (AATSR), and the Advanced Very High Resolution Radiometer (AVHRR) instruments on board the NOAA and MetOp satellites. Also assimilated are data from the geostationary Spinning Enhanced Visible and Infrared Imager (SEVIRI), a dataset not included in global FOAM. All data are quality controlled using the Bayesian procedure of 60. Furthermore a bias correction scheme, based on comparisons to in-situ and AATSR data, is applied to the AMSRE, AVHRR, and SEVIRI observations. A full description of the satellite 
data types and the scheme used to bias correct them can be found in ${ }^{61}$. To highlight the data coverage available, Fig 3 shows maps of the data coverage for a 10 day period of August 2008. It is worth noting from this figure the lack of AMSRE data near the coast and also that SEVIRI data is only available south of $60^{\circ} \mathrm{N}$. Data availability for satellites is reduced in the winter, not shown, due to increased cloud cover and rain, this is especially true for the infrared satellites (AATSR, the two AVHRR instruments, and SEVIRI).

The other major changes to the data assimilation system, as compared to global FOAM, apply to the specification of the forecast error covariance matrix. In the vertical, information is simply applied down to the base of the instantaneous (time-step by time-step) mixed layer, with the mixed layer defined as the $0.2{ }^{\circ} \mathrm{C}$ change in temperature from the surface (this is the same definition as used in ${ }^{62}$ ). The horizontal forecast error covariances, as in ${ }^{10}$, are specified by two Second Order Auto Regressive (SOAR) functions: a function describing synoptic-scale, atmospherically driven, error correlations and a function for shorter length scale, ocean driven, error correlations. Constant length scales - $450 \mathrm{~km}$ for the synoptic-scale and $30 \mathrm{~km}$ for the shorter length scale - are used in these functions. The magnitudes (the variances) of the two terms are allowed to vary both spatially and temporally. Specifically, spatial maps of the variances were calculated for December-January-February, March-April-May, June-July-August, and September-October-November, with linear interpolation used to form a continuous annual cycle. To find the variances, the National Meteorological Center (NMC) method of ${ }^{63}$ was used determine the spatial structure, with the Höllingsworth and Lonnberg method of ${ }^{64}$ used to determine the amplitude. The seasonal synoptic and mesoscale variances used by FOAM-AMM are shown in Fig 4 and reveal that mesoscale variability is dominant throughout the year. Also evident are the substantial temporal changes that occur on the shelf, particularly in the Norwegian trench and the large magnitude of the synoptic and mesoscale variances near the Faroes and Shetland Islands, which is an area of large SST gradients.

\section{System Validation}

\section{Hindcasts}

Any new modelling system requires systematic validation before being considered for integration into the operational suites. The existing POLCOMS-AMM system provides a baseline target from which to compare FOAM-AMM. A series of hindcasts are performed to assess the skill and reliability of the new system. The barotropic tidal dynamics are assessed first. An assessment is then made of the baroclinic dynamics using a full two-year hindcast integration. The FOAM-AMM hindcast is compared against observations and the operational POLOMS-AMM system for the hindcast period.

\section{Tides}

Harmonic analysis of the FOAM-AMM and POLCOMS-AMM systems show greater skill for FOAM-AMM in terms of root mean square (RMS) error of Sea Surface Height (SSH) amplitude and phase versus tide gauge data gathered from the British Oceanographic Data Centre (BODC). An analysis of tidal SSH amplitude and phase is presented in Table 1 for a selection of the most significant tidal constituents. The SSH RMS error is about $10 \%$ better in FOAM-AMM than POLCOMS-AMM whereas the mean error is similar in both systems with the exception of the M2 tidal constituent. The majority of the mean amplitude error for M2 in FOAM-AMM is due to an underestimation of the M2 amplitude in the Irish sea. The modeled positions of the amphidromes for M2 are shown in the co-tidal chart of Fig 5 which may be compared to observations as depicted in ${ }^{65}$. The positioning of the degenerate amphidrome in southern Norway is better placed in FOAM-AMM. The incorrect position of the degenerate Norwegian amphidrome partially explains the large improvement in terms of RMS phase error for the M2 constituent in FOAM-AMM. 
Spatial comparison between the two systems and observations of tidal constituents M2 and $\mathrm{S} 2$ is made in Fig 6 . In Fig 6 the absolute error between POLCOMS-AMM and observations is subtracted from the absolute error between FOAM-AMM and observations. From Fig 6 regions of relative strengths and weakness in each system can be identified. Blue indicates improved skill in FOAM-AMM over POLCOMS-AMM. For the M2 SSH amplitude, the eastern Irish Sea is an area of weakness for FOAM-AMM. In the eastern Irish Sea FOAMAMM tends to underestimate the SSH amplitude. In contrast for the S2 constituent, FOAMAMM performs well for most of the Irish Sea. More generally, as may be seen in Fig 7, the SSH amplitude in FOAM-AMM tends to be slightly smaller than POLCOMS-AMM. POLCOMS-AMM tends to have amplitudes that are too large in areas of large tidal amplitude such as the Bristol Channel. Although the harmonic analysis statistics show a general improvement in FOAM-AMM over POLCOMS-AMM, particular regions require further refinement in the FOAM-AMM system particularly in relation to underestimating the amplitude.

\begin{tabular}{|c|c|c|c|c|c|c|c|c|}
\hline & \multicolumn{4}{|c|}{ RMS } & \multicolumn{4}{c|}{ MEAN } \\
\hline & \multicolumn{2}{|c|}{ Amplitude (cm) } & \multicolumn{2}{c|}{ Phase (deg) } & \multicolumn{2}{c|}{ Amplitude (cm) } & \multicolumn{2}{c|}{ Phase (deg) } \\
\hline & POLC & FOAM & POLC & FOAM & POLC & FOAM & POLC & FOAM \\
\hline O1 & 2.2 & 1.9 & 17.2 & 15.7 & -1.5 & -1.3 & -3.8 & -2.2 \\
\hline K1 & 1.9 & 1.8 & 20.6 & 17.1 & -0.2 & -0.2 & -11.9 & -8.4 \\
\hline N2 & 3.1 & 2.9 & 19.1 & 21.6 & 0.6 & 0.4 & 1.2 & 2.7 \\
\hline M2 & 12.0 & 10.3 & 21.1 & 14.7 & -0.2 & -4.7 & -0.1 & -0.2 \\
\hline S2 & 6.1 & 3.7 & 14.3 & 12.8 & 1.6 & -0.4 & 1.0 & 0.5 \\
\hline
\end{tabular}

Table 1: Elevation amplitude and phase RMS and mean errors (model-observations) for tidal constituents 01, K1, N2, M2, S2 for both POLCOMS (POLC) and FOAM-AMM.

\section{Baroclinic hindcasts}

Free and SST assimilating hindcasts of FOAM-AMM are integrated for the two-year period of 2007-2008. This period facilitates the inter-comparison of FOAM-AMM against archived operational POLCOMS-AMM data. Initial temperature and salinity fields are interpolated from the analysis fields of the assimilative FOAM $1 / 12^{\circ}$ North Atlantic system for November 2006. All other fields are taken at rest for the initial condition. The FOAM $1 / 12^{\circ}$ North Atlantic system assimilates data through the water column and thus provides a good deep-water initial condition off the shelf. However, as profile data are limited on the shelf and the fact that the FOAM North Atlantic system does not include dynamical features of the shelf such as tides, a number of spin up years are required for the on shelf physics. The system is run without any assimilation for a period of one year until November 2007 as an initial spin-up year. The system is restarted and run for a further spin-up year starting again from November 2006 using the restart from the end of the first spin-up year. Finally, both a free run and an assimilative run are started from November 2006, running until the end of 2008 using the restart produced at the end of the 2 nd spin-up year. For the free run, the temperature and salinity statistics between the 2nd spin-up year and the final two-year hindcast are very 
similar. Thus the adjustment to the initial condition from the assimilative FOAM $1 / 12^{\circ}$ North Atlantic analysis fields is largely attained over the first spin up year and any model drift thereafter is small between subsequent model years.

One of the key objectives of the new FOAM-AMM system is to improve the representation of SST. Thus the daily averaged surface temperature fields from the free and assimilative two year hindcast runs of FOAM-AMM and the existing POLCOMS-AMM operational archive are compared to the Operational Sea Surface Temperature and Sea Ice Analysis (OSTIA $)^{66}$ SST fields for the hindcast period. It must be noted that OSTIA is not an independent data source, both because the NWP derived fluxes use OSTIA data as a reference SST and because the data assimilation uses data common to OSTIA. However, both the POLCOMS-AMM and FOAM-AMM systems use the same Haney correction scheme when applying the NWP fluxes and thus OSTIA is a useful data source for comparing the two non-assimilative systems. Comparisons to independent data in the form of salinity and temperature profiles are presented in Table 2. Here we show comparisons to OSTIA in order to provide a broad overview of the spatial distribution of the SST errors that is not so easily discernable with the data sparse profiles.

The 2008 time series of the daily mean and RMS differences between the model runs and OSTIA for both the entire AMM domain and the on-shelf MRCS domain are compared in Fig 8. The free run of FOAM-AMM has an annual mean warm bias relative to OSTIA of $0.33^{\circ}$ C. This warm bias is most marked during winter, which is in contrast to POLCOMS-AMM, which has its largest bias in summer. The POLCOMS-AMM summer SST warm bias is a result of the model over stratifying. The annual mean SST bias in the FOAM-AMM system may be related to a combination of the turbulence scheme, the simple light attenuation scheme and the prescribed fluxes. The surface mixed layer in FOAM-AMM is deeper than that of POLCOMS-AMM. Thus any surface cooling by the Haney correction is reduced and the depth integrated heat content gained over the summer may be overestimated and thus leading to the warm SST bias in winter.

The assimilative FOAM-AMM hindcast has a mean discrepancy with OSTIA of $0.12^{\circ} \mathrm{C}$ and a similarly much reduced RMS difference with OSTIA of $0.39^{\circ} \mathrm{C}$ compared to $0.71^{\circ} \mathrm{C}$ for the free run. The SST data assimilation results in a much improved model analysis field of SST throughout the year. The mean and RMS errors for all models are slightly larger in the on shelf MRCS region than over the entire AMM domain. Fig 9 shows the 2008 annual and monthly mean difference for February and August between OSTIA and the 3 model runs for the entire AMM domain. Clearly visible are the summertime warm bias in POLCOMS-AMM and the winter warm bias in FOAM-AMM, which are also visible in the time series of Fig 8.

There are two distinct areas of error for both POLCOMS-AMM and FOAM-AMM in the annual mean. The first is the on shelf region and the second is between the northern boundary of the domain and the Faroes. It is found in the case of FOAM-AMM that the coarse and smoothed bathymetry inherited from POLCOMS-AMM leads to a shelf break current that is too strong due to the improved HPG scheme in FOAM-AMM. The strong shelf slope current leads to too much advection of relatively warm water along the shelf break. Using bathymetry derived directly from the $1 \mathrm{~nm}$ NOOS bathymetric dataset reduces the shelf slope error significantly. However, further refinement of the shelf slope bathymetry may be required to simulate the shelf slope current with greater skill.

With regards to the SST error near the northern boundary, sensitivity tests reveal that both POLCOMS-AMM and FOAM-AMM are very sensitive to the prescription of SSH on the lateral boundaries. The boundary SSH affects both surface and the bottom water flows over the Iceland-Shetland Ridge through channels such as the Faroe Bank Channel and small changes of SSH can lead to large changes in the currents in this region. The overflows in each system are potentially too weak, resulting in high temperature waters east of Iceland. Modelling the overflow of cold dense Arctic water through the narrow straits is particularly difficult. The resolution required both in the vertical to capture bottom water cascades over the sills and the horizontal to capture the geometry of the narrow channels is currently prohibitive to implement across the entire AMM domain in an operational forecast system. 
Whilst it is clear that the SST data assimilation improves the system's representation of SST, it is also important to consider whether the data assimilation has a negative impact on sub-surface water structure and the tidal mixing fronts. One of the key features of the NWS is the seasonal tidal mixing fronts between seasonally stratified water such as in the central North Sea and tidal mixed waters such as those of the southern bight. As the assimilation applies constant increments to SST through each day, there is a risk that it may smooth out the fronts and consequently adversely affect the 3D structure.

To assess the tidal frontal locations and summer stratification comparisons of the surface minus bed temperatures of the model runs is made against gridded ICES data ${ }^{67}$ following ${ }^{49}$. Fig 10 shows the summer surface - bed temperature difference for the ICES climatology and the models. The frontal location is indicated by the $0.5^{\circ} \mathrm{C}$ contour in surfacebed temperature difference. The location of the front in NEMO-AMM is more close to the ICES data set than POLCOMS-AMM overall but it appears to over estimate mixing in the German Bight. The difference in the stratification between ICES and FOAM-AMM and POLCOMS-AMM is also shown in the bottom panels of Fig 10. POLCOMS-AMM has much more stratification than either ICES or FOAM-AMM. As noted by ${ }^{49}$ this arises from the turbulence model used in POLCOMS-AMM.

The locations of the tidal mixing fronts for the assimilative and free runs of FOAMAMM do not differ significantly. Thus the SST assimilation does not degrade the frontal positions. However, the level of stratification, particularly in the Norwegian trench is different, with the free run closer to ICES than the assimilative run. One source of the discrepancy is simply that the SST is significantly corrected in the assimilative model run, particularly for the Norwegian trench area. However, the bottom water temperature in the trench is also cooler in the assimilative run than the free run. The origins of this discrepancy occur in winter months when the North Sea is mixed and the assimilation cools the water along the lip of the trench, which then feeds into the trench proper. Table 2 shows a comparison between the free and assimilative runs of FOAM-AMM and 558 profiles from profiling buoys and ships that are available over the Global Telecommunications System (GTS) on the shelf during August 2008, mostly in the North Sea. These data are not assimilated and thus constitutes a completely independent data set. The assimilative run does not significantly alter the salinity profile comparisons and improves the temperature profiles. Thus whilst the change in the stratification in the Norwegian trench due to the SST assimilation requires further investigation, the overall effect on the shelf of the assimilation is to improve the SST without degrading salinity profiles or tidal mixing frontal positions. Table 3 is an equivalent comparison for winter months. However, the number of profiles available during winter is significantly less than summer. For the combined months of January and February there were only 348 observations available from the GTS across the entire MRCS domain.

\begin{tabular}{|c|c|c|c|c|}
\hline & \multicolumn{2}{|c|}{ RMS } & \multicolumn{2}{c|}{ MEAN } \\
\hline & $\begin{array}{c}\text { Temperature } \\
\left({ }^{\circ} \mathrm{C}\right)\end{array}$ & $\begin{array}{c}\text { Salinity } \\
(\mathrm{PSU})\end{array}$ & $\begin{array}{c}\text { Temperature } \\
\left({ }^{\circ} \mathrm{C}\right)\end{array}$ & $\begin{array}{c}\text { Salinity } \\
(\mathrm{PSU})\end{array}$ \\
\hline Assimilative & 0.824 & 1.791 & -0.230 & 0.866 \\
\hline Free & 1.062 & 1.800 & -0.673 & 0.870 \\
\hline
\end{tabular}

Table 2: RMS and mean differences between profile data and the assimilative and nonassimilative hindcasts of NEMO-AMM for August 2008 over the MRCS domain. 


\begin{tabular}{|c|c|c|c|c|}
\hline & \multicolumn{2}{|c|}{ RMS } & \multicolumn{2}{c|}{ MEAN } \\
\hline & $\begin{array}{c}\text { Temperature } \\
\left({ }^{\circ} \mathrm{C}\right)\end{array}$ & $\begin{array}{c}\text { Salinity } \\
(\mathrm{PSU})\end{array}$ & $\begin{array}{c}\text { Temperature } \\
\left({ }^{\circ} \mathrm{C}\right)\end{array}$ & $\begin{array}{c}\text { Salinity } \\
(\mathrm{PSU})\end{array}$ \\
\hline Assimilative & 0.338 & 0.738 & 0.088 & 0.254 \\
\hline Free & 0.436 & 0.762 & 0.176 & 0.202 \\
\hline
\end{tabular}

Table 3: RMS and mean differences between profile data and the assimilative and nonassimilative hindcasts of NEMO-AMM for January and February 2008 over the MRCS domain.

\section{Conclusions and future developments}

A new operational forecasting system, FOAM-AMM, has been developed for the European NWS. The system uses NEMO as its core physics engine and includes SST data assimilation. An outline of some of the major dynamical features of the NWS is reviewed, for which several key enhancements required for NEMO have been developed. Details of these key developments and a description of the system in general are outlined including the adaption of the FOAM assimilation scheme for SST data assimilation in a tidally driven shelf seas forecast system.

Initial verification of the system includes assessing the FOAM-AMM system compared to an existing operational shelf seas forecast system POLCOMS-AMM. Harmonic analysis of the dominant tidal constituents show that in general FOAM-AMM is better than or equal to POLCOMS-AMM for SSH amplitude and phase. However, in the eastern Irish Sea FOAM-AMM is found to have weaker tides than observations and is an area that requires further refinement.

A two year fully baroclinic hindcast for 2007-2008 is also compared against archived operational fields from POLCOMS-AMM for the same period. The hindcasts reveal that the annual RMS SST errors in POLCOMS-AMM and FOAM-AMM without assimilation are similar, but with areas and seasons of weakness and strengths in each.

The addition of SST data assimilation markedly reduces the RMS SST errors. Furthermore, an analysis of the seasonal stratification on the shelf and tidal mixing fronts shows that the assimilation does not significantly alter the tidal mixing frontal positions. The locations of fronts in FOAM-AMM are in general closer to the ICES data set than POLCOMSAMM with some exceptions including the German Bight.

The system continues to evolve and more detailed analysis of specific dynamics and regions continue to highlight specific features and areas that need to be addressed. Developments under investigation include the replacement of the climatological Baltic boundary condition with real time data from a Baltic model. Specification from hydrological models of the river outflows is also being assessed. An improved coordinate system that allows a constant surface box domain wide is being developed to allow uniform specification of fluxes. The light attenuation scheme will be replaced by a three band scheme and spatial variance of the light attenuation coefficient based on satellite climatologies is also being developed. Similarly, the coefficient of bottom friction may be varied depending on seabed types. A wetting and drying scheme is planned at NOC (following the one implemented in POLCOMS) which should allow for improved tidal dynamics, particularly in the Irish Sea. The data assimilation scheme will be updated to use NEMOVAR ${ }^{68}$ and an improvement of the 
specification of the error covariance will be made. In addition to SST data assimilation, both profile data and altimeter data will be assimilated.

The FOAM-AMM system is also coupled to the ecosystem model ERSEM. ${ }^{13}$ The coupled system continues to develop in parallel to the physical model and replaces the existing POLCOMS-ERSEM. Finally, a fully coupled atmosphere-ocean model using a version of FOAM-AMM for the ocean component focused on waters around the U.K. is being developed using the $\mathrm{OASIS}^{69}$ coupler.

\section{Acknowledgments:}

Funding for this research is gratefully acknowledged from the Ministry of Defence, from the European Community's Seventh Framework Programme FP7/2007-2013 under grant agreement $n^{\circ} 218812$ (MyOcean) and from Ocean2025: the NERC's core programme in ocean science.

Works Cited:

1. Flather RA, Proctor R, and Wolf J. 1991. Oceanographic Forecast Models. In Computer Modelling In The Envirnomental Sciences, Farmer, DG and Rycroft, MJ, Eds. Clarendon Press, Oxford. pp. 15-30.

2. Flather RA. 2000. Existing operational oceanography. Coastal Engineering 41(1-3): 13-40.

3. Holt JT and James ID. 2001. An s coordinate density evolving model of the northwest European continental shelf 1, Model description and density structure. J. Geophys. Res. 106(C7): 14015-14034.

4. Holt M, Li Z, and Osborne J. 2003. Real-time forecast modelling for the NW european shelf seas. In Elsevier Oceanography Series, H. Dahlin, NCFKN and Petersson, SE, Eds. Elsevier. pp. 484-489.

5. Siddorn JR, Allen JI, Blackford JC, Gilbert FJ, Holt JT, Holt MW, Osborne JP, Proctor R, and Mills DK. 2007. Modelling the hydrodynamics and ecosystem of the North-West European continental shelffor operational oceanography. Journal of Marine Systems 65(1-4): 417429.

6. Platt T, Sathyendranath S, White G, Fuentes-Yaco C, Zhai L, Devred E, and Tang C. 2010. Diagnostic Properties of Phytoplankton Time Series from Remote Sensing. Estuaries and Coasts 33(2): 428-439.

7. Bell MJ, Forbes RM, and Hines A. 2000. Assessment of the FOAM global data assimilation system for real-time operational ocean forecasting. Journal of Marine Systems 25(1): 122.

8. Annan JD and Hargreaves JC. 1999. Sea surface temperature assimilation for a threedimensional baroclinic model of shelf seas. Continental Shelf Research 19: 1507-1520.

9. Martin MJ, Hines A, and Bell MJ. 2007. Data assimilation in the FOAM operational short-range ocean forecasting system: a description of the scheme and its impact. Quarterly Journal of the Royal Meteorological Society 133(625): 981-995.

10. Storkey D, et al. 2010. Forecasting the ocean state using NEMO: The new FOAM system. Journal of Operational Oceanography 3: 3-15. 
11. Madec G. 2008. NEMO ocean engine. Note du Pole de modélisation. Institut Pierre-Simon Laplace (IPSL), France. No 27 ISSN No 1288-1619

12. Baretta JW, Ebenhöh W, and Ruardij P. 1995. The European regional seas ecosystem model, a complex marine ecosystem model. Netherlands Journal of Sea Research 33(3-4): 233246.

13. Edwards KP, Barciela RM, and Butenschon M. In Preparation. Validation of the NEMOERSEM operational ecosystem model for the North West European Continental Shelf.

14. Proctor R and James ID. 1996. A fine-resolution 3D model of the Southern North Sea. Journal of Marine Systems 8(3-4): 285-295.

15. Holt JT, James ID, and Jones JE. 2001. An s coordinate density evolving model of the northwest European continental shelf 2, Seasonal currents and tides. J. Geophys. Res. 106(C7): 14035-14053.

16. Holt JT, Allen JI, Proctor R, and Gilbert F. 2005. Error quantification of a high-resolution coupled hydrodynamic-ecosystem coastal-ocean model: Part 1 model overview and assessment of the hydrodynamics. Journal of Marine Systems 57(1-2): 167-188.

17. Ryder P. 2007. Fast Track Marine Core Serice: Startegic Implementation Plan. Available from: http://www.gmes.info/pages-principales/library/implementationgroups/marine-core-service-mcs/

18. Huthnance JM. 1984. Slope Currents and "JEBAR". Journal of Physical Oceanography 14(4): 795-810.

19. Hill AE, Hickey BM, Shillington FA, Strub PT, Brink KH, Barton ED, and Thomas AC. 1998. Eastern Ocean Boundaries: Coastal segment (E). In The Sea: The Global Coastal Ocean, Volume 11, Regional Studies and Syntheses, Robinson, AR and Brink, KH, Eds. John Wiley

20. Torres R and Barton ED. 2006. Onset and development of the Iberian poleward flow along the Galician coast. Continental Shelf Research 26(10): 1134-1153.

21. Haynes R and Barton ED. 1990. A poleward flow along the atlantic coast of the iberian penninsula. J. Geophys. Res. 95(C7): 11425-11441.

22. New AL and Pingree RD. 2000. An intercomparison of internal solitary waves in the Bay of Biscay and resulting from Korteweg-de Vries-Type theory. Progress In Oceanography 45(1): 1-38.

23. Pingree RD, Mardell GT, and New AL. 1986. Propagation of internal tides from the upper slopes of the Bay of Biscay. Nature 321(6066): 154-158.

24. Simpson JH. 1998. The Celtic Seas. In The Sea: The Global Coastal Ocean, Robinson, AR and Brink, KH, Eds. John Wiley and Sons, New York. pp. 659-698.

25. Hansen B and Østerhus S. 2000. North Atlantic-Nordic Seas exchanges. Progress In Oceanography 45: 109-208.

26. Johnson C, Sherwin T, Smythe-Wright D, Shimmield T, and Turrell W. 2010. Wyville Thomson Ridge Overflow Water: Spatial and temporal distribution in the Rockall Trough. Deep Sea Research Part I: Oceanographic Research Papers 57(10): 1153-1162.

27. Simpson JH and Bowers D. 1981. Models of stratification and frontal movement in shelf seas. Deep Sea Research Part A. Oceanographic Research Papers 28(7): 727-738.

28. Holt J and Proctor R. 2008. The seasonal circulation and volume transport on the northwest European continental shelf: A fine-resolution model study. J. Geophys. Res. 113(C6): C06021.

29. Rossiter JR. 1954. The North Sea Storm Surge of 31 January and 1 February 1953. Philosophical Transactions of the Royal Society of London. Series A, Mathematical and Physical Sciences 246(915): 371-400.

30. Souza AJ and Simpson JH. 1997. Controls on stratification in the Rhine ROFI system. Journal of Marine Systems 12(1-4): 311-323.

31. Bendtsen J, Gustafsson KE, Söderkvist J, and Hansen JLS. 2009. Ventilation of bottom water in the North Sea-Baltic Sea transition zone. Journal of Marine Systems 75(1-2): 138-149.

32. Otto L, Zimmerman JTF, Furnes GK, Mork M, Saetre R, and Becker G. 1990. Review of the physical oceanography of the North Sea. Netherlands Journal of Sea Research 26(2-4): 161-238.

33. Wakelin S, Holt J, and Proctor R. 2009. The influence of initial conditions and open boundary conditions on shelf circulation in a $3 D$ ocean-shelf model of the North East Atlantic. Ocean Dynamics 59(1): 67-81. 
34. Song Y and Haidvogel D. 1994. A Semi-implicit Ocean Circulation Model Using a Generalized Topography-Following Coordinate System. Journal of Computational Physics 115(1): 228-244.

35. Levier B, Tréguier AM, Madec G, and Garnier V. 2007. Free surface and variable volume in the NEMO code. MERSEA IP report WP09-CNRS-STR03-1A

36. Arakawa A and Lamb VR. 1981. A Potential Enstrophy and Energy Conserving Scheme for the Shallow Water Equations. Monthly Weather Review 109(1): 18-36.

37. Zalesak ST. 1979. Fully multidimensional flux-corrected transport algorithms for fluids. Journal of Computational Physics 31(3): 335-362.

38. Courant R, Friedrichs K, and Lewy H. 1928. Über die partiellen Differenzengleichungen der mathematischen Physik. Mathematische Annalen 100(1): 32-74.

39. Madec G, Delecluse P, Crépon M, and Lott F. 1996. Large-Scale Preconditioning of DeepWater Formation in the Northwestern Mediterranean Sea. Journal of Physical Oceanography 26(8): 1393-1408.

40. Mellor GL, Ezer T, and Oey L-Y. 1994. The Pressure Gradient Conundrum of Sigma Coordinate Ocean Models. Journal of Atmospheric and Oceanic Technology 11(4): 11261134.

41. Liu H and O'Dea EJ. In Preparation. A new pressure Jacobian horizontal pressure gradient method for hybrid vertical coordinate ocean modelling.

42. Flather RA. 1976. A tidal model of the northwest European continental shelf. Mem. Soc. R. Sci. Liege 10(6): 141-164.

43. Flather RA. 1981. Results from a model of the northeast Atlantic relating to the Norwegian coastal current. In The Norwegian Coastal Current, Sætre, R and Mork, M, Eds. Bergen University, Bergen, Norway. pp. 427-458.

44. Martinsen EA and Engedahl H. 1987. Implementation and testing of a lateral boundary scheme as an open boundary condition in a barotropic ocean model. Coastal Engineering 11(5-6): 603-627.

45. Umlauf L and Burchard H. 2003. A generic length-scale equation for geophysical turbulence models. Journal of Marine Research 61: 235-265.

46. Canuto VM, Howard A, Cheng Y, and Dubovikov MS. 2001. Ocean Turbulence. Part I: OnePoint Closure Model-Momentum and Heat Vertical Diffusivities. Journal of Physical Oceanography 31(6): 1413-1426.

47. Rodi W. 1987. Examples of calculation methods for flow and mixing in stratified fluids J. Geophys. Res. 92(C5): 5305-5328.

48. Umlauf L and Burchard H. 2005. Second-order turbulence closure models for geophysical boundary layers. A review of recent work. Continental Shelf Research 25(7-8): 795-827.

49. Holt J and Umlauf L. 2008. Modelling the tidal mixing fronts and seasonal stratification of the Northwest European Continental shelf. Continental Shelf Research 28(7): 887-903.

50. Craig PD and Banner ML. 1994. Modeling Wave-Enhanced Turbulence in the Ocean Surface Layer. Journal of Physical Oceanography 24(12): 2546-2559.

51. Galperin B, Kantha LH, Hassid S, and Rosati A. 1988. A Quasi-equilibrium Turbulent Energy Model for Geophysical Flows. Journal of the Atmospheric Sciences 45(1): 55-62.

52. Young EF and Holt JT. 2007. Prediction and analysis of long-term variability of temperature and salinity in the Irish Sea. J. Geophys. Res. 112(C1): C01008.

53. Haney RL. 1971. Surface Thermal Boundary Condition for Ocean Circulation Models. Journal of Physical Oceanography 1(4): 241-248.

54. Martin MJ, Hines A, and Bell MJ. 2007. Data Assimilation in the FOAM operational shortrange ocean forecasting system: a description of the scheme and its impact. Quarterly Journal of the Royal Meteorological Society 133: 981-995.

55. Lorenc AC, Bell RS, and Macpherson B. 1991. The Meteorological Office analysis correction data assimilation scheme. Quarterly Journal of the Royal Meteorological Society 117: 5989.

56. Bloom SC, Takacs LL, Da Silva AM, and Ledvina D. 1996. Data Assimilation Using Incremental Analysis Updates. Monthly Weather Review 124: 1256-2170.

57. Annan JD and Hargrreaves JC. 1999. Sea surface temperature assimilation for a threedimensional baroclinic model of shelf seas. Continental Shelf Research 19: 1507-1520.

58. Larson J, Høyer JL, and She J. 2007. Validation of a hybrid optimal interpolation and Kalman filter scheme for sea surface temperature and assimilation. Journal of Marine Systems 65: 122-133. 
59. Donlon CJ, et al. 2007. The GODAE High Resolution Sea Surface Temperature Pilot Project (GHRSST-PP). Bulletin of the American Meteorological Society 88: 1197-1213.

60. Lorenc AC and Hammon 0. 1988. Objective quality control of observations using Bayesian methods. Theory, and a practical implementaion. Quarterly Journal of the Royal Meteorological Society 114: 515-543.

61. Donlon CJM, M. J. Stark, J. Roberts-Jones, J. Fiedler, E. Wimmer, W. 2011. The Operational Sea Surface Temperature and Sea Ice Analysis (OSTIA). Rem. Sens. Env In Press.:

62. Montégut C, Madec G, Fischer AS, Lazar A, and Iudicone D. 2004. Mixed layer depth over the global ocean: an examination of profile data and a profile-based climatology. J. Geophys. Res. 109: c12003.

63. Parrish DF and Derber JC. 1992. The National Meteorological Center's spectral statisticalinterpolation analysis system. Monthly Weather Review 12: 1747-1763.

64. Hollingsworth A and Lonnberg P. 1986. The statistical structure of short range forecast errors as determined from radiosonde data. Tellus 38A: 111-136.

65. Howarth MJ and Pugh DT. 1983. Observations of tides over the continental shelf of northwest Europe. In Physical Oceanography of Coastal and Shelf Seas, Johns, B, Ed. Elsevier, Amsterdam. pp. 133-85.

66. Stark JD, Donlon CJ, Martin MJ, and McCulloch ME. An operational, high resolution real time, global sea surface temperature analysis system. in Oceans '07 IEEE Aberdeen, conference proceedings. Marine challenges: coastline to deep sea. 2007. Aberdeern, Scotland: IEEE.

67. The International Council for the Exploration of the Sea database. Available from: http://www.ices.dk/ocean/aspx/HydChem/hydChem.aspx.

68. Mogensen KS, Balmaseda MA, Weaver A, Martin MJ, and Vidard A. NEMOVAR: A variational data assimilation system for the NEMO ocean model. in ECMWF newsletter. Summer 2009.

69. Redler R, Valcke S, and Ritzdorf H. 2010. OASIS4 - a coupling software for next generation earth system modelling. Geosci. Model Dev. 3(1): 87-104. 

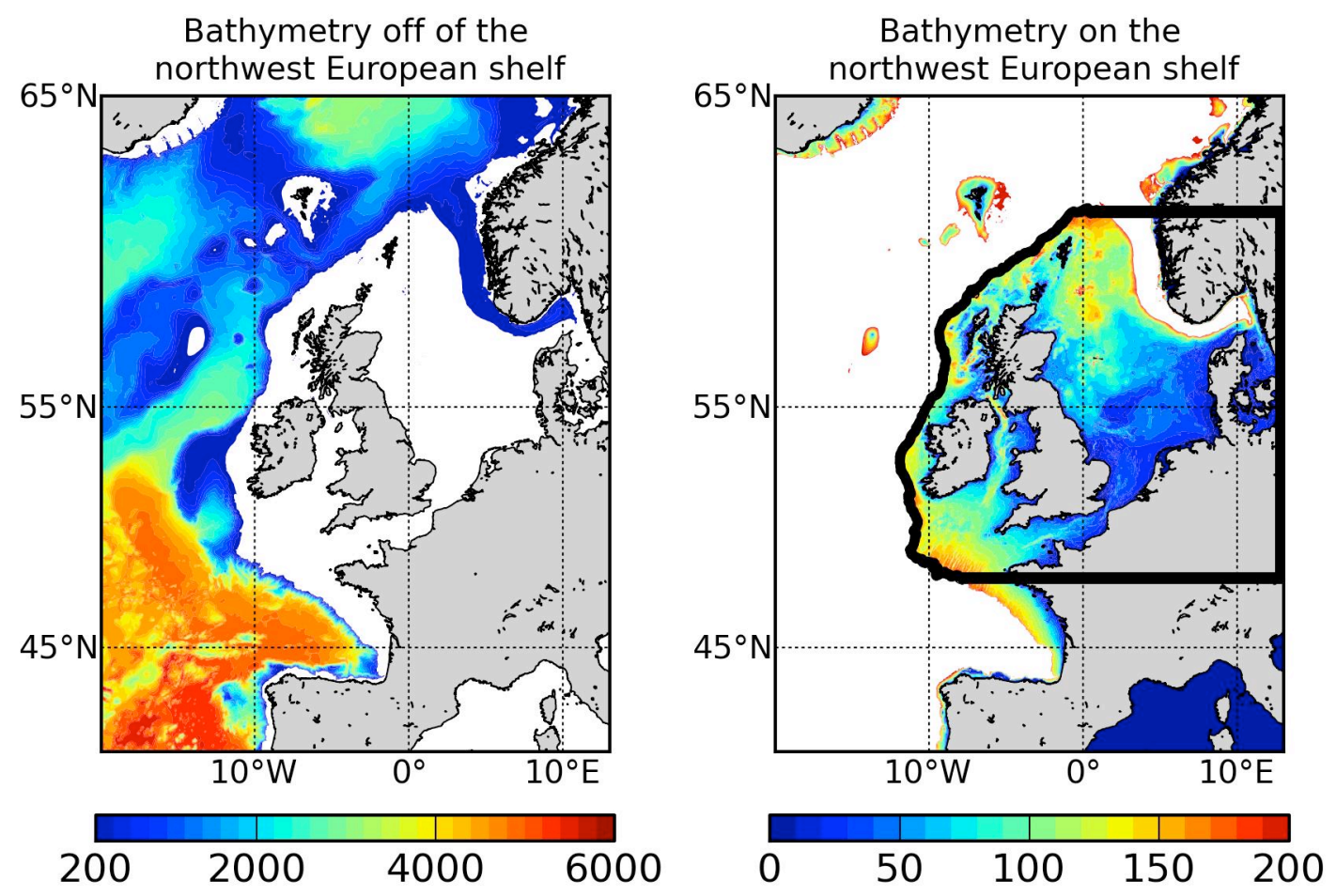

Fig 1: AMM domain. Left panel: Off shelf NOOS bathymetry > 200m. Right panel: On shelf NOOS bathymetry $<200 \mathrm{~m}$, with the MRCS domain boundary indicted in thick black.

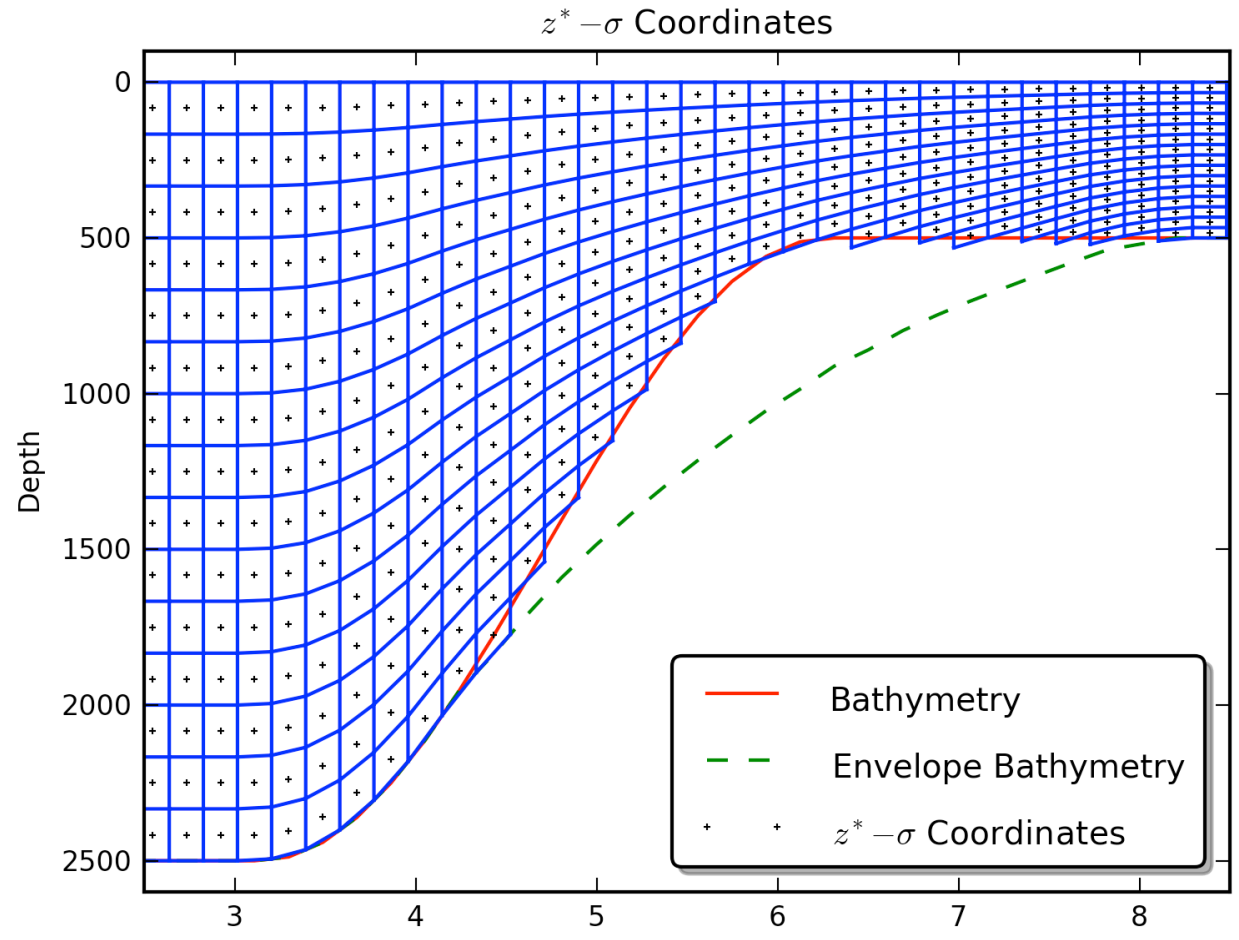

Fig 2: $z^{*}-\sigma$ coordinates with envelope bathymetry dashed. This generic figure is conceptual and thus the units for the lateral direction (x-axis) and vertical direction (y-axis) are nondimensional. 


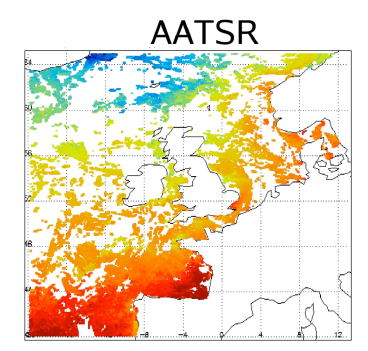

SEVIRI
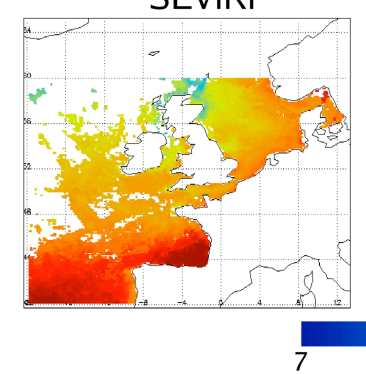

NOAA-AVHRR

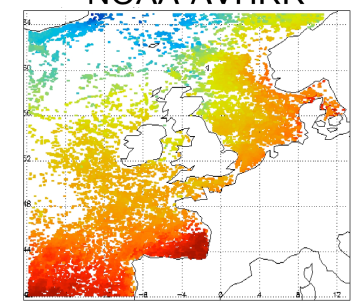

METOP-AVHRR

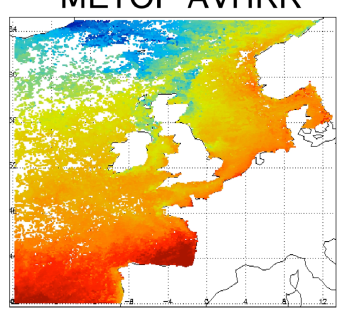

14.5

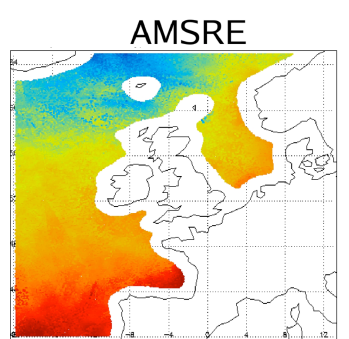

In-Situ

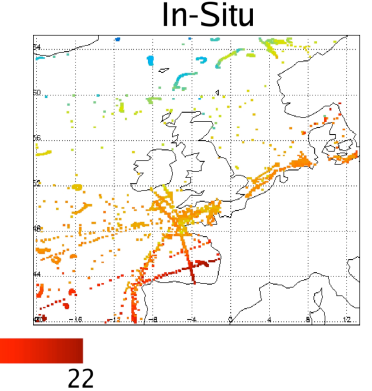

Fig 3. Composites of the data available from each satellite and in-situ sources for assimilation over 10 days between the $1^{\text {st }}$ and $10^{\text {th }}$ August 2008. Colours indicate temperature in degrees Celsius.
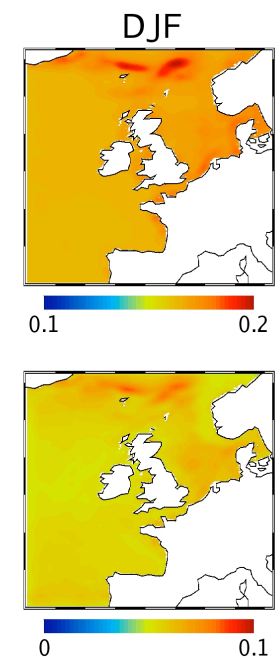
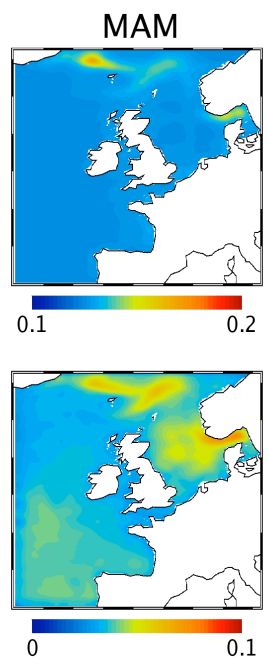

JJA
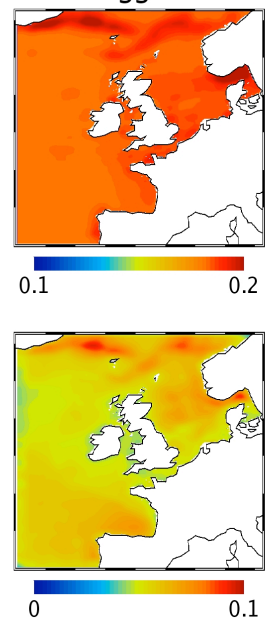
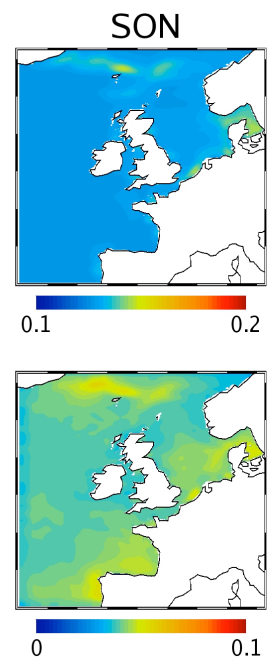

Fig 4. Variance fields used by the NEMO Shelf data assimilation scheme. The top row shows the mesoscale variance, while the bottom row shows the synoptic-scale variance. The columns represent the seasons: December-January-February (DJF), March-April-May (MAM), June-JulyAugust (JJA), and September-October-November (SON). Units are $\mathrm{K}^{2}$.

\begin{tabular}{|c|c|c|c|c|c|c|c|c|}
\hline & \multicolumn{4}{|c|}{ RMS } & \multicolumn{4}{c|}{ MEAN } \\
\hline & \multicolumn{2}{|c|}{ Amplitude (cm) } & \multicolumn{2}{c|}{ Phase (deg) } & \multicolumn{2}{c|}{ Amplitude (cm) } & \multicolumn{2}{c|}{ Phase (deg) } \\
\hline & POLC & FOAM & POLC & FOAM & POLC & FOAM & POLC & FOAM \\
\hline O1 & 2.2 & 1.9 & 17.2 & 15.7 & -1.5 & -1.3 & -3.8 & -2.2 \\
\hline K1 & 1.9 & 1.8 & 20.6 & 17.1 & -0.2 & -0.2 & -11.9 & -8.4 \\
\hline N2 & 3.1 & 2.9 & 19.1 & 21.6 & 0.6 & 0.4 & 1.2 & 2.7 \\
\hline M2 & 12.0 & 10.3 & 21.1 & 14.7 & -0.2 & -4.7 & -0.1 & -0.2 \\
\hline S2 & 6.1 & 3.7 & 14.3 & 12.8 & 1.6 & -0.4 & 1.0 & 0.5 \\
\hline
\end{tabular}

Table 1: Elevation amplitude and phase RMS and mean errors (model-observations) for tidal constituents $\mathrm{O} 1, \mathrm{~K} 1, \mathrm{~N} 2, \mathrm{M} 2, \mathrm{~S} 2$ for both POLCOMS (POLC) and FOAM-AMM. 

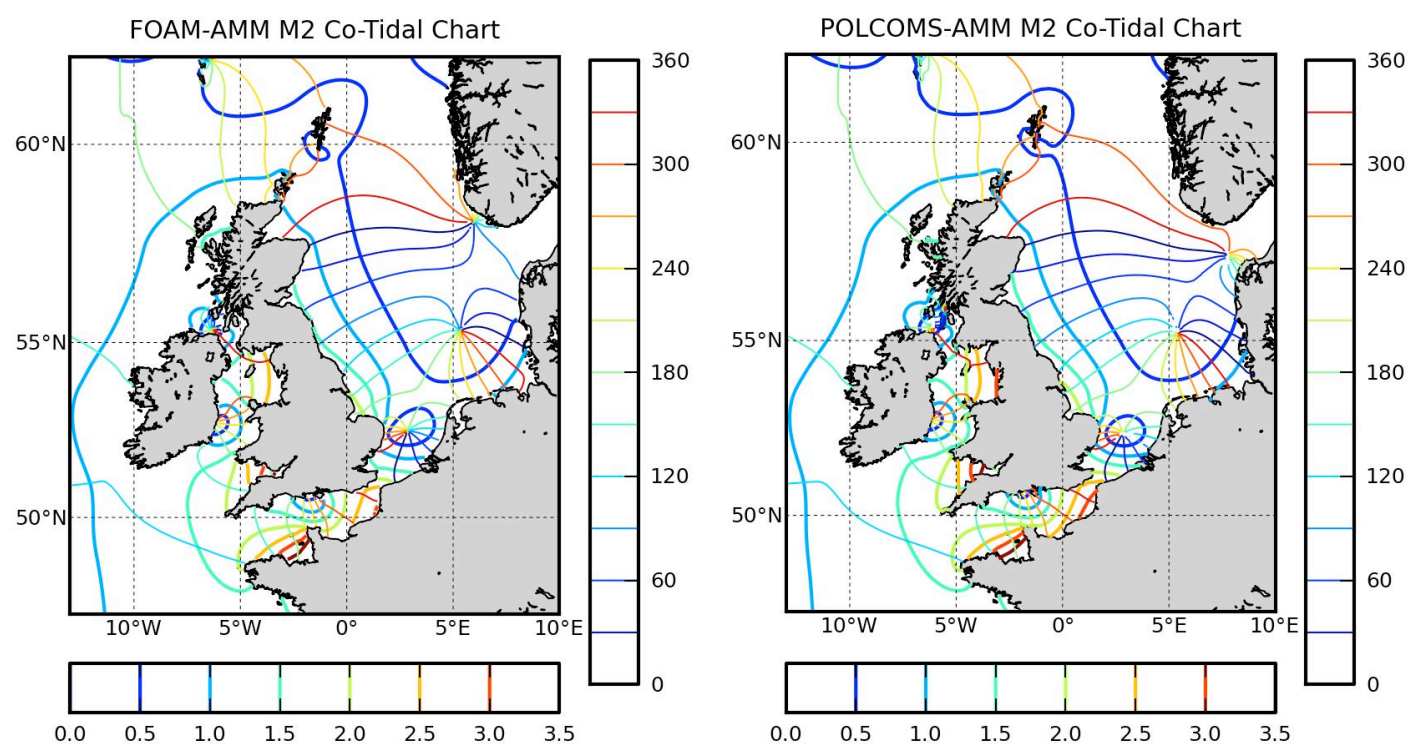

Fig 5: M2 Co-tidal chart for FOAM-AMM (left) and POLCOMS (right). Co-range lines are thick and values are given on the horizontal colourbars. Co-phase lines are thin and values are given on the vertical colourbars. 

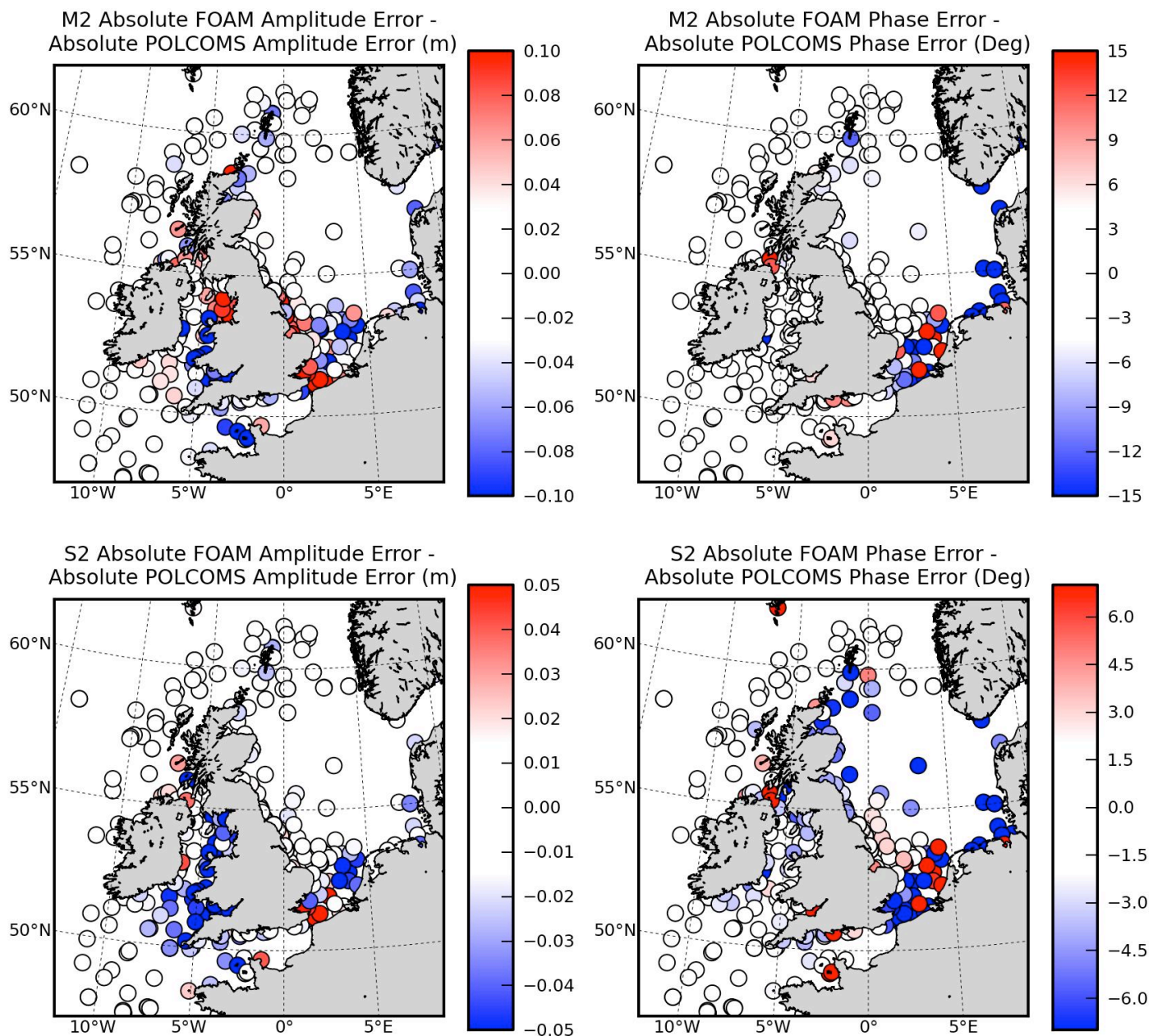

Fig 6: Difference (FOAM-AMM minus POLCOMS-AMM) of absolute SSH error from observations in amplitude (left) and phase (right) for tidal constituents M2 (top) and S2 (bottom). 

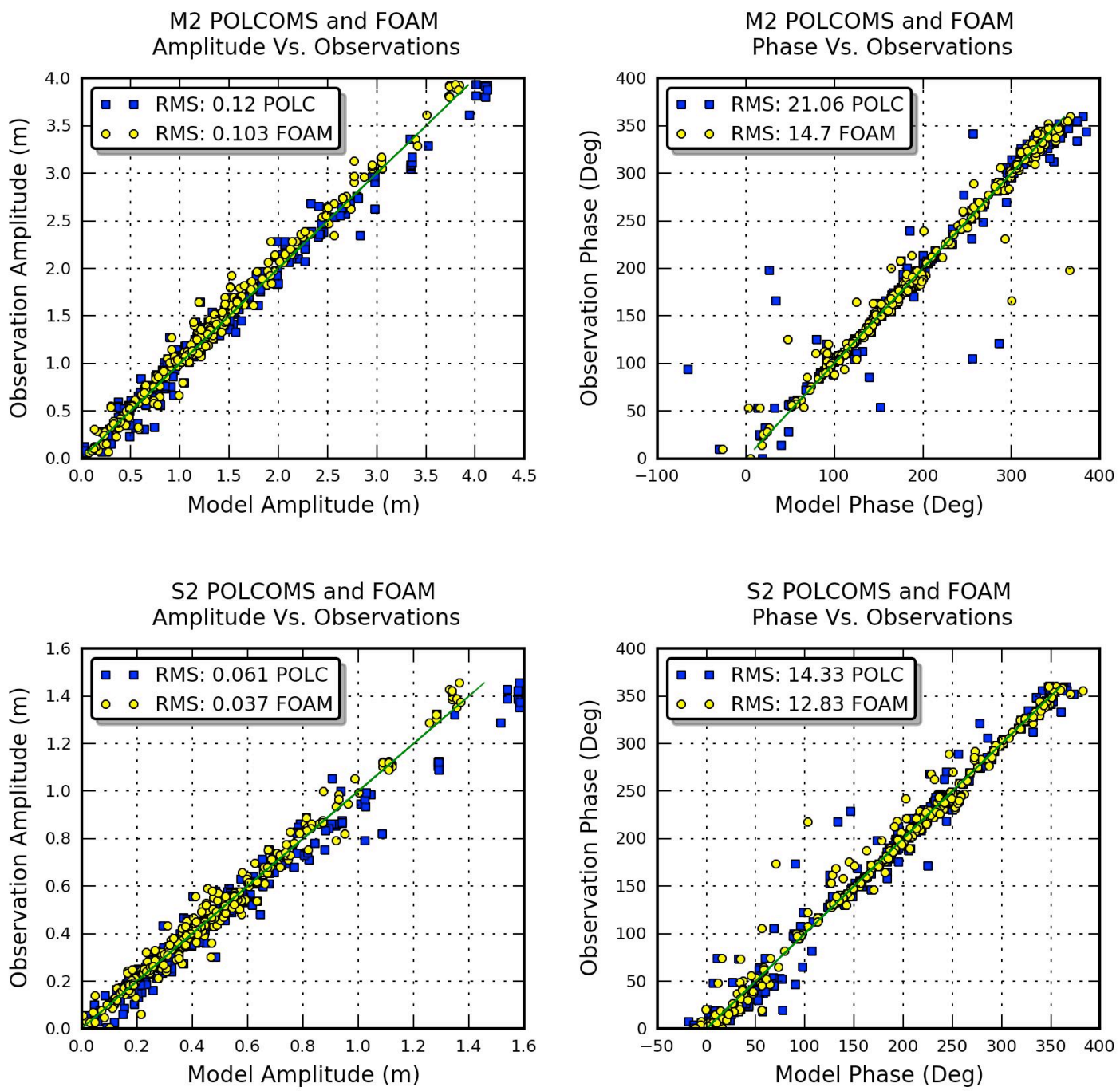

Fig 7: SSH amplitude (left) and phase (right) of POLCOMS (blue square) and FOAM-AMM (yellow circle) against observations for tidal constituents M2 (top) and S2 (bottom). 

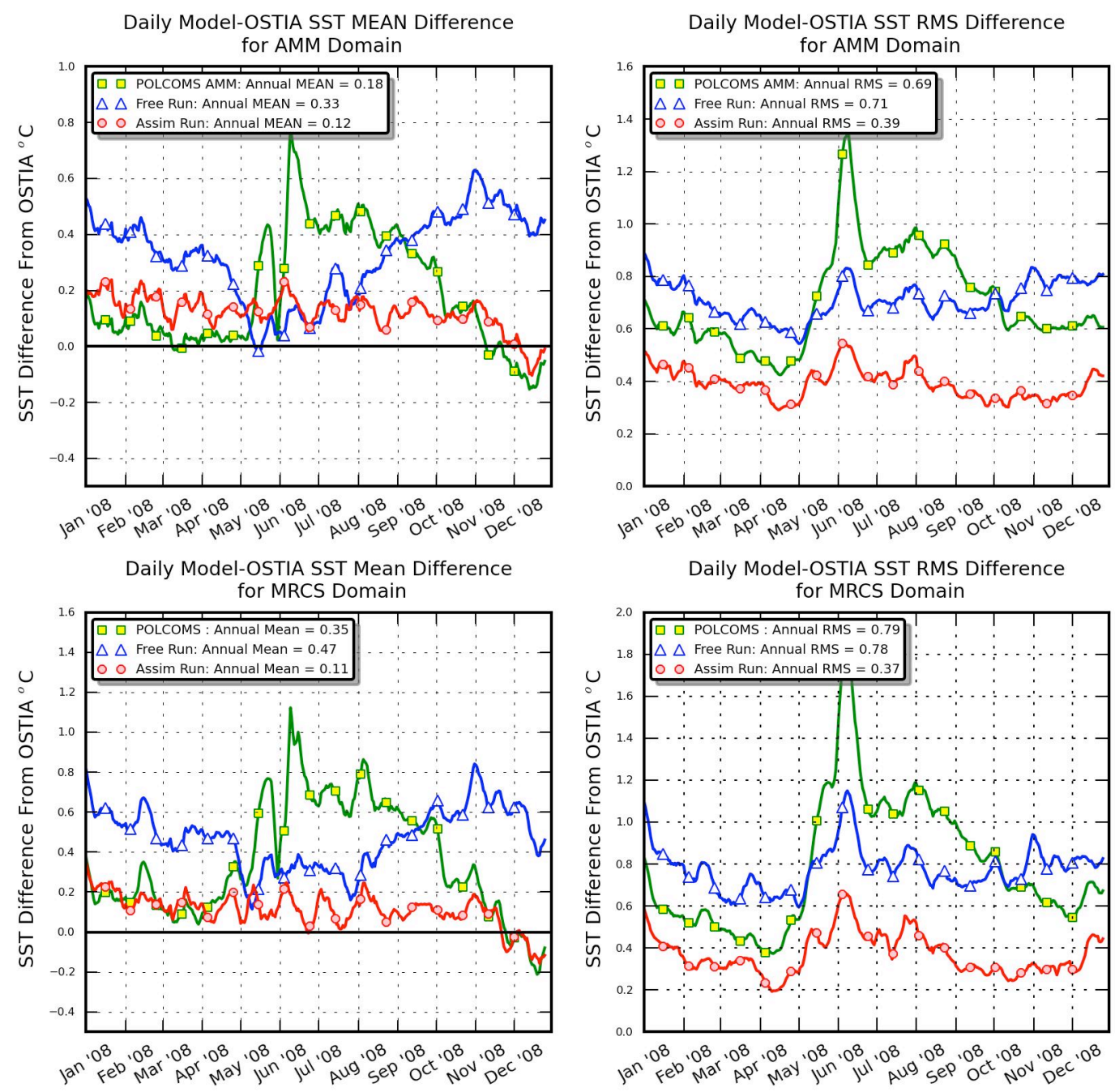

Fig 8: Top panels are the 10 day running mean of RMS (left) and mean (right) differences from OSTIA SST over the AMM domain between POLCOMS-AMM, FOAM-AMM free run and FOAM-AMM assimilative run daily for 2008. Bottom panels are the 10 day running mean of RMS (left) and mean (right) differences from OSTIA SST over the MRCS domain for POLCOMS-AMM, FOAM-AMM free run and FOAM-AMM assimilative run. 


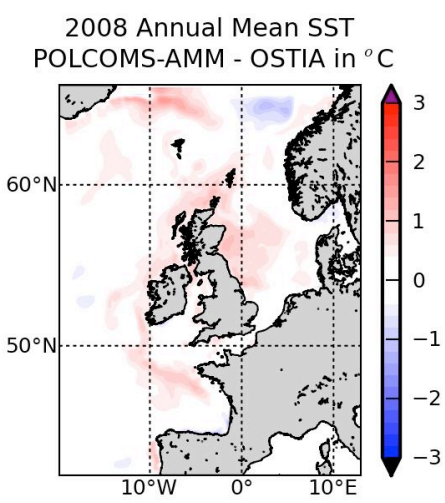

Feb 2008 Mean SST

POLCOMS-AMM - OSTIA in ${ }^{\circ} \mathrm{C}$

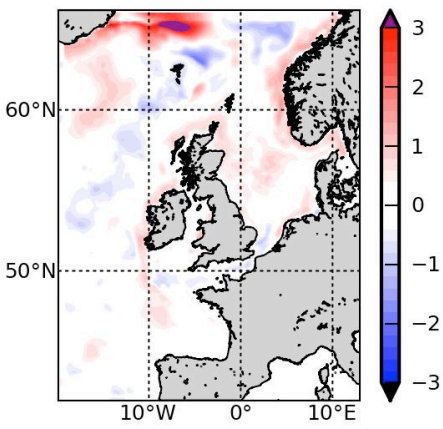

Aug 2008 Mean SST

POLCOMS-AMM - OSTIA in ${ }^{\circ} \mathrm{C}$

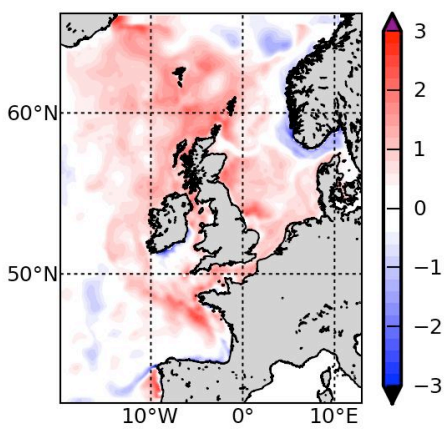

2008 Annual Mean SST

FOAM-AMM (Free) - OSTIA in ${ }^{\circ} \mathrm{C}$

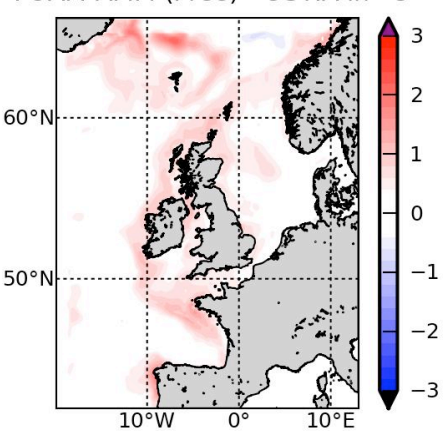

Feb 2008 Mean SST FOAM-AMM (Free) - OSTIA in ${ }^{\circ} \mathrm{C}$

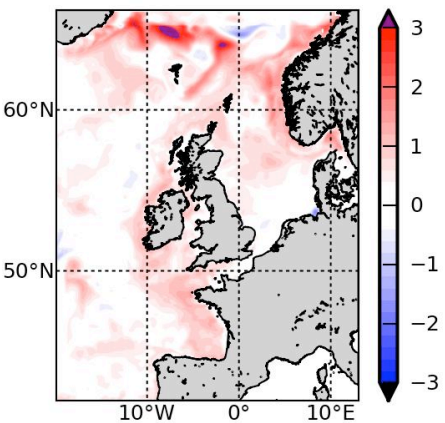

Aug 2008 Mean SST FOAM-AMM (Free) -OSTIA in ${ }^{\circ} \mathrm{C}$

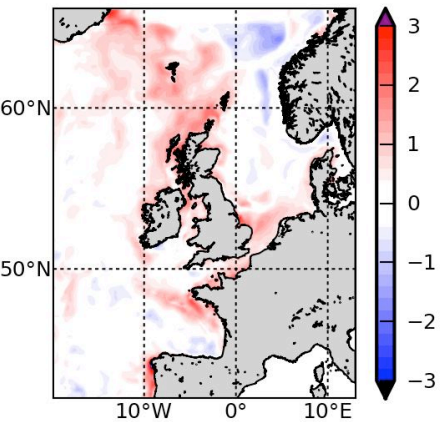

2008 Annual Mean SST

FOAM-AMM (Assim.) - OSTIA in ${ }^{\circ} \mathrm{C}$

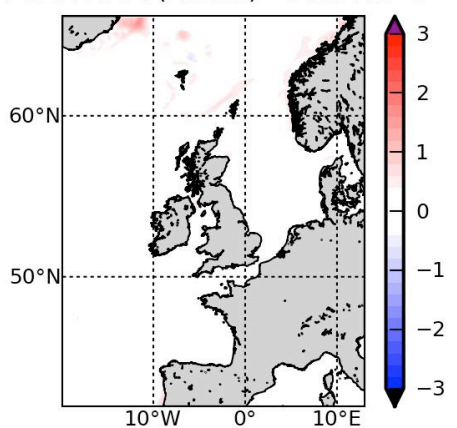

Feb 2008 Mean SST

FOAM-AMM (Assim) - OSTIA in ${ }^{\circ} \mathrm{C}$

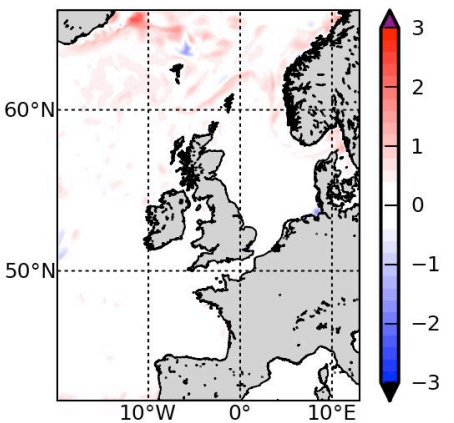

Aug 2008 Mean SST

FOAM-AMM (Assim.) - OSTIA in ${ }^{\circ} \mathrm{C}$

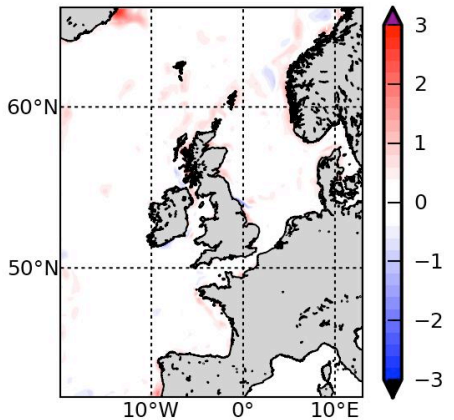

Fig 9: Top row is the 2008 annual mean difference between POLCOMS-AMM (left), FOAMAMM free (center), FOAM-AMM assimilative (right) and OSTIA in ${ }^{\circ} \mathrm{C}$. Middle row is the February 2008 monthly mean difference. Bottom row is the August 2008 monthly mean difference. 

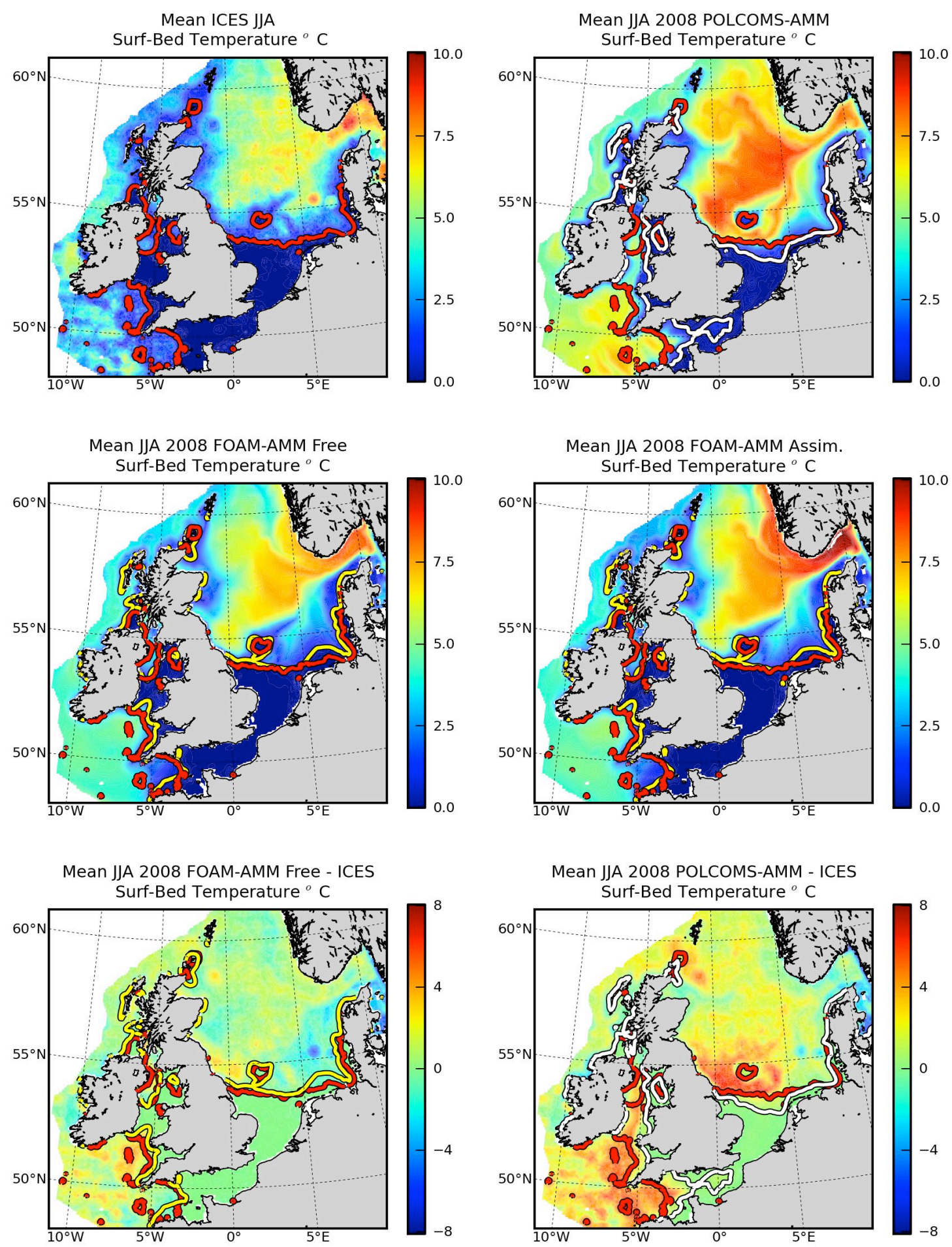

Fig 10: Top left panel is the mean ICES surface-bed temperature for summer (JJA). Top right panel is the mean POLCOMS-AMM surface-bed temperature for JJA 2008. Centre left is the mean FOAM-AMM non-assimilative surface-bed for JJA 2008. Centre right is the same for FOAM-AMM assimilative. Bottom left is the JJA mean difference of surface-bed temperature between ICES and FOAM-AMM (free). Bottom right is the JJA mean difference between ICES and POLCOMS-AMM. Thick contours indicate mean frontal locations using the $0.5^{\circ} \mathrm{C}$ surface-bed contour for the ICES data (red), POLCOMS-AMM data (white) and FOAM-AMM data (yellow). 


\begin{tabular}{|c|c|c|c|c|}
\hline & \multicolumn{2}{|c|}{ RMS } & \multicolumn{2}{c|}{ MEAN } \\
\hline & $\begin{array}{c}\text { Temperature } \\
\left({ }^{\circ} \mathrm{C}\right)\end{array}$ & $\begin{array}{c}\text { Salinity } \\
(\mathrm{PSU})\end{array}$ & $\begin{array}{c}\text { Temperature } \\
\left({ }^{\circ} \mathrm{C}\right)\end{array}$ & $\begin{array}{c}\text { Salinity } \\
(\mathrm{PSU})\end{array}$ \\
\hline Assimilative & 0.824 & 1.791 & -0.230 & 0.866 \\
\hline Free & 1.062 & 1.800 & -0.673 & 0.870 \\
\hline
\end{tabular}

Table 2: RMS and mean differences between profile data and the assimilative and nonassimilative hindcasts of NEMO-AMM for August 2008 over the MRCS domain. 